\title{
RELATIONS AMONG POOR SLEEP, ANXIETY AND DEPRESSION AMONG THE STUDENTS OF HEALTH SCIENCES
}

\section{ANDRUŠKIENĖ Jurgita, BARSEVIČIENĖ Šarūnė, MAŽIONIENĖ Asta, VIRBALIENĖ Akvilè}

Klaipèda State University of Applied Sciences, Klaipeda, Lithuania

\begin{abstract}
The research in the area of health sciences students' sleep quality and mood disorders is lacking in Lithuania, as well as other European countries. The aim of this study was to compare prevalence of poor sleep, anxiety and depression among the students according to the study programmes and to assess the relations among poor sleep, depression and anxiety. The study sample consisted of 672 Klaipeda State University of Applied Sciences students (95.5\% were female), from 18 to 46 years of age. Sleep quality was evaluated by Pittsburgh Sleep Quality Index, anxiety by Hospital Anxiety and Depression Scale, sociodemographic questions were used. The chi-square test or Fisher exact test was used to estimate association between categorical variables. P-values less than 0.05 were interpreted as statistically significant. Poor sleep was more prevalent among Beauty Therapy (26.4\%, 95\% CI 22.2-30.56) and Nursing (21.3\%, 95\% CI 17.42 - 25.17) students, as compared with persons studying in Oral Health programmes (14.8\%, 95\% CI 11.46 - 18.17), p<0.05. Depression mean score was higher in Beauty Therapy students (4.76), as compared to Oral Health (3.69) students, $p<0.05$. Beauty Therapy (9.99) or Physiotherapy students (8.24) had higher anxiety mean score, as compared to Oral Health students (7.14), $p<0.05$. Anxiety mean score was significantly higher (8.45) among the ones with disturbed sleep, as compared to normally sleeping students (5.86), $p<0.001$. Depression mean score (4.77) was higher among the students having disturbed sleep, as compared to the students which sleep was not disturbed (2.87), p<0.001. Poor sleep and anxiety were more prevalent among the students aged 20 years and older as compared to the students, aged 18 and 19 years. Second and third year students more often had poor sleep or anxiety as compared to the first-year students. Poor sleep and anxiety were more common among Beauty Therapy and Physiotherapy students than among Oral Health Students. Among the students who slept poorly, symptoms of anxiety and depression were statistically significantly more frequent than those students whose sleep was not disturbed. Depression and anxiety mean scores were statistically significantly higher among the students who had poor sleep, as compared to the ones who had normal sleep, in all age and year of studying groups.
\end{abstract}

Keywords: Anxiety; Depression; Health sciences; Poor sleep; Students. 


\section{Background}

Students experience more stress, as compared to general population, and the stressors are specific. Being away from home, adjusting to new living environment, anxiety about the future (Sarokhani et al., 2013) and academic stress due to enormous amount of knowledge to be acquired in a limited short time, lack of leisure activities (Misra \& McKean, 2000), all those stressors increased risk of psychoemotional disturbances. Medical studies are the most challenging, because students experience constant exposure to death and suffering. As the consequences of these stressors, medical students had mood, sleep disturbances, emotional exhaustion (Pagnin et al., 2014) and worsened academic achievements (Ahrberg et al., 2012).

Prevalence of anxiety varied from 7.7 to $65.5 \%$, depression - from 6.0 to $66.5 \%$ (Hope et al., 2014) among the students of medical schools in the UK, Europe and North America. The prevalence of anxiety and depression before medical training among the students in Malaysia university was $55.6 \%$ and $1.8 \%$, respectively. The prevalence of anxiety during medical training increased from $41.1 \%$ to $56.7 \%$. The prevalence of depression during medical training increased from $12 \%$ to $30 \%$ (Yusoff et al., 2013). The prevalence of insomnia among the nursing students in Italy was $26.7 \%$ (Angelone et al., 2011). More than one third (31\%) of the medical students from University of Tartu, aged 19-33 years, evaluated their sleep quality as satisfactory, poor or very poor (Veldi et al., 2005). Undiagnosed sleep problems can exacerbate mental stress in medical students with possibly long-term consequences for individual's health (Palatty et al., 2011).

Epidemiological data suggest that the prevalence of mild to severe depression, anxiety and stress among qualified nurses in Hong Kong was 35.8\%, 37.3\% and 41.1\%, respectively (Cheung et al., 2016). Psychoemotional status of the students was reflected by the rates of psychoactive substances use. The prevalence of substance abuse was $20.4 \%$ among medical students. An increase in substance abuse was observed in the latter years of medical education. The most common reasons for substance use were relief from psychological stress (72.4\%) (Arora et al., 2016).

Health risk factors affected nearly half of the students: $40 \%$ of the university students' sample in USA was overweight/obese, and 19\% of students had increased total cholesterol levels. Only $44 \%$ met the recommended 30 min of exercise 5 days per week. Forty-one percent reported elevated depressive symptoms and $28 \%$ had anxiety. Inverse relationships existed among depression/anxiety and healthy lifestyle beliefs/behaviors. Students entering health professional 
schools were at high risk for depression, anxiety, and unhealthy behaviors, which could be averted through screening and early evidence-based interventions (Mazurek et al., 2016). Burnout, stress, and depression were common for the students of health sciences such as those in medical and dental school (Dyrbye et al., 2014; Elani et al., 2014).

There is an evidence to suggest that insufficient sleep and irregular sleep-wake patterns resulting chronic sleep debt are present at alarming levels in the student population, especially studying medicine or health sciences. The research in the area of students 'sleep quality and mood disorders is lacking in Lithuania, as well as other European countries. There were no studies in Lithuania analyzing the sleep quality among students in the field of health sciences. The aims of this study were: i) To compare the scores of sleep quality, depression and anxiety among the students, according to age, year of studying and study programme; ii) To establish associations among depression, anxiety and poor sleep in age groups, according to the study programme and a year of studying.

\section{Methodology}

\section{Sample}

The survey was conducted in February and March 2016. The study sample consisted of the students ( $\mathrm{N}=618,95.1 \%$ were female, from 18 to 46 years old) of Klaipeda State University of Applied Sciences. The first $(n=258 ; 41.7 \%)$, second $(n=201 ; 32.5 \%)$ and third $(n=159 ; 25.8 \%)$ year students were involved in the study (Table 1). Response rate was $88.3 \%$. Mean age of the students was 20.65 ( $\mathrm{SD}=2.899)$. Students were grouped according to the study programmes: there were groups of Oral Health (Dental Hygiene and Dental Assisting) ( $\mathrm{n}=108 ; 17.5 \%)$, Beauty Therapy $(\mathrm{n}=152 ; 24.6 \%)$, Nursing $(\mathrm{n}=138 ; 22.3 \%)$, Physiotherapy $(\mathrm{n}=110 ; 17.8 \%)$ and Social Work $(n=110 ; 17.8 \%)$. The grouping was performed in order to ensure the even distribution of the respondents as much as possible. Students were also grouped according to the age: 18-19 years $(n=206 ; 33.4 \%), 20(n=164 ; 26.5 \%)$ and $\geq 21$ years $(n=248 ; 40.1 \%)$. Frequencies of the subjectively perceived sleep quality and anxiety were compared according to age, studying year and study programme. The study was approved by Bioethics Committee of Klaipeda State University of Applied Sciences. 


\section{Data collection and tools}

Pittsburgh Sleep Quality Index (PSQI) (Buysse et al., 1989) was used for subjective sleep quality evaluation. PSQI is a self-rated questionnaire which assesses sleep quality over a 1month time interval. 19 individual items generate seven "component" scores: subjective sleep quality, sleep latency, sleep duration, habitual sleep efficiency, sleep disturbances, use of sleeping medication, and daytime dysfunction. The sum of scores for these seven components yielded one global score. Total PSQI score $<5$ was evaluated as good sleep quality; $>5$ - poor sleep.

Hospital Anxiety and Depression (HAD) scale (Zigmond and Snaith, 1983), a selfassessment scale was used to identify states of depression, anxiety and emotional distress among the students. The HAD scale has in total 14 items, with responses being scored on a scale of $0-3$, with 3 indicating higher symptom frequencies. Score for each subscale (anxiety and depression) ranged from 0-21 with scores categorized as follows: normal (0-7), disorder (>7). Scores for the entire scale (emotional distress) ranged from 0-42, with higher scores indicating more distress. Prior to completing the scale respondents were asked to "fill it complete in order to reflect how they have been feeling during the past week" (Zigmond and Snaith, 1983). Additional sociodemographic questions about respondents' age, gender, study program and year of the studying were included in the questionnaire.

\section{Data analysis}

The Chi-square test or Fisher exact test were used to estimate association between categorical variables. Students $t$ test was used to compare means and $Z$ criteria was used to test the difference in two population proportions. Data analysis performed using SPSS 20.0.P-values less than 0.05 were interpreted as statistically significant.

\section{Results}

Poor sleep was more prevalent among Beauty Therapy (26.4\%, 95\% CI 22.2-30.56) and Nursing $(21.3 \%, 95 \%$ CI 17.42 - 25.17) students, as compared to Oral Health programme (14.8\%, 95\% CI 11.46 - 18.17), p<0.05. Significantly higher PSQI scores indicating poorer sleep quality were assessed in Social work (6.75), Physiotherapy (7.11), Nursing (6.75) and Beauty Therapy (7.78) students, as compared to Oral Health (5.44) students, $\mathrm{p}<0.05$ (see Table 1). 
Table 1. Global PSQI, depression and anxiety scores, according to students' age, year of studying and study programme

\begin{tabular}{|c|c|c|c|}
\hline \multirow[t]{2}{*}{ Variables } & Global PSQI score & Depression score & Anxiety score \\
\hline & Mean (SD) & Mean (SD) & Mean (SD) \\
\hline \multicolumn{4}{|l|}{ Age groups } \\
\hline $18-19$ & $6.60(3.186)$ & $3.48(2.740)$ & $7.79(4.045)$ \\
\hline 20 & $6.78(2.995)$ & $3.91(2.855)$ & $7.96(4.019)$ \\
\hline$\geq 21$ & 7.07 (3.097) & $4.68(3.272) * *$ & $9.25(4.203) * *$ \\
\hline \multicolumn{4}{|l|}{ Year of studying } \\
\hline First & $6.67(3.146)$ & $3.57(2.685)$ & $7.75(4.094)$ \\
\hline Second & $7.00(3.173)$ & $4.14(3.044) *$ & $8.12(3.857)$ \\
\hline Third & $6.97(2.943)$ & $4.83(3.388) * *$ & $9.89(4.263) * *$ \\
\hline \multicolumn{4}{|l|}{ Study programme } \\
\hline Oral Health & $5.44(3.316)$ & $3.69(3.280)$ & $7.14(4.199)$ \\
\hline Beauty Therapy & $7.78(3.093) * *$ & $4.76(3.297) *$ & $9.99(4.463) * *$ \\
\hline Nursing & $6.75(3.097) *$ & $3.90(2.740)$ & $8.01(3.543)$ \\
\hline Physiotherapy & $7.11(2.944) * *$ & $3.97(2.738)$ & $8.24(3.926) *$ \\
\hline Social Work & $6.75(2.542) *$ & $3.84(2.938)$ & $8.21(4.019)$ \\
\hline
\end{tabular}

$* \mathrm{p}<0.05$, as compared to the reference group (italic)

$* * \mathrm{p}<0.001$, as compared to the reference group (italic)

Depression mean score was higher among 21 years old students (4.68), as compared to 18-19 years (3.48), $\mathrm{p}<0.001$, proving that older students had greater risk to have depression as compared with younger ones. Third (4.83) or second year (4.14) students had significantly higher depression mean scores, as compared with the first year (3.57) students (Table 1). Depression mean score was higher in Beauty Therapy students (4.76), as compared to Oral Health (3.69) students, $\mathrm{p}<0.05$. Anxiety mean score was significantly higher among the students older than 21 years $(9.25)$, as compared to younger (18-19 years old) students (7.79), $\mathrm{p}<0.001$. Third year students had higher anxiety mean score (9.89), as compared to first year students (7.75), p<0.001. Beauty Therapy (9.99) or Physiotherapy students (8.24) had higher anxiety mean score, as compared to Oral Health students (7.14), $\mathrm{p}<0.05$ (see Table 1).

The students (18-19 years old) whose sleep was disturbed, had significantly higher depression mean score (3.81), as compared to the ones who had normal sleep (2.63), $\mathrm{p}<0.05$ (see 
Table 2). Anxiety score was higher (8.50) among the students (18-19 years) who had disturbed sleep, as compared to those having normal sleep (5.95), $\mathrm{p}<0.001$. Prevalence of anxiety was higher among the students who had sleep disturbances (57.7\%), as compared to normal sleep (31.6\%), $\mathrm{p}<0.05$.

Table 2. Mean scores and prevalence (percent) of depression and anxiety among the students, according to the sleep quality in age groups

\begin{tabular}{|l|c|c|c|c|c|c|}
\hline \multirow{4}{*}{ HADS } & \multicolumn{2}{|c|}{$\mathbf{1 8 - 1 9}$ years $(\mathbf{n = 2 0 6})$} & \multicolumn{2}{c|}{ 20 years $(\mathbf{n = 1 6 4})$} & \multicolumn{2}{|c|}{$\geq 21$ years (n=248) } \\
\cline { 2 - 7 } & $\begin{array}{c}\text { Normal } \\
(n=57)\end{array}$ & $\begin{array}{c}\text { Sleep } \\
\text { disturbance } \\
(\mathrm{n}=149)\end{array}$ & $\begin{array}{c}\text { Normal } \\
(n=57)\end{array}$ & $\begin{array}{c}\text { Sleep } \\
\text { disturbance } \\
(\mathrm{n}=107)\end{array}$ & $\begin{array}{c}\text { Normal } \\
(n=72)\end{array}$ & $\begin{array}{c}\text { Sleep } \\
\text { disturbance } \\
(\mathrm{n}=176)\end{array}$ \\
\hline Depression & 2 & 17 & 2 & $15 *$ & 6 & $41 *$ \\
$($ HADS $>7)$ & $(3.5 \%)$ & $(11.4 \%)$ & $(3.5 \%)$ & $(14.0 \%)$ & $(8.3 \%)$ & $(23.3 \%)$ \\
\cline { 2 - 7 } & 2.63 & $3.81 *$ & 2.70 & $4.56 * *$ & 3.28 & $5.25 * *$ \\
& $(2.476)$ & $(2.775)$ & $(2.228)$ & $(2.950)$ & $(2.854)$ & $(3.266)$ \\
\hline Anxiety & 18 & $86 *$ & 15 & $65 *$ & 27 & $124 * *$ \\
$($ HADS $>7)$ & $(31.6 \%)$ & $(57.7 \%)$ & $(26.3 \%)$ & $(60.7 \%)$ & $(37.5 \%)$ & $(70.5 \%)$ \\
\cline { 2 - 7 } & 5.95 & $8.50 * *$ & 5.95 & $9.03 * *$ & 7.07 & $10.14 * *$ \\
& $(3.538)$ & $(4.015)$ & $(2.948)$ & $(4.113)$ & $(3.396)$ & $(4.183)$ \\
\hline
\end{tabular}

(italic).

Data is presented as $n(\%)$ or mean $(S D), * p<0.05 . * * p<0.001$, as compared to the reference group

20 years old students which had disturbed sleep, also had higher prevalence of depression (14.0\%) and higher depression mean score (4.56), as compared to normal sleep, 3.5\%, $\mathrm{p}<0.05$ and 2.70, $\mathrm{p}<0.001$, respectively (Table 2). Students (20 years old) who had disturbed sleep, had higher prevalence of anxiety (60.7\%) and higher score of anxiety (9.03), as compared to the students which had normal sleep, 26.3\%, p<0.05 and 5.95, $<<0.001$, respectively. The students older than 21 years, whose sleep was disturbed, had significantly higher prevalence of depression (23.3\%), as compared to normal sleep (8.3\%), $\mathrm{p}<0.05$, as well as higher depression score, 5.25 vs $3.28, \mathrm{p}<0.005$ (Table 2). Prevalence of anxiety among the students ( $\geq 21$ years old) with poor sleep, was higher $(70.5 \%)$, as compared to normally sleeping students $(37.5 \%)$, as well as the score of anxiety was higher among the students with disturbed sleep (10.14), as compared to normally sleeping ones (7.07), $\mathrm{p}<0.001$ (Table 2). 
Prevalence of depression (17.2\%), as well as mean score of depression (4.47) were higher among Oral health students having poor sleep, as compared to those whose sleep was normal, $2.3 \%$ and $2.55, \mathrm{p}<0.05$, respectively. Prevalence of depression $(22.8 \%)$, as well as mean score of depression (5.31) were higher among Beauty Therapy students having poor sleep, as compared to those whose sleep was normal, $7.9 \%$ and 3.13, $\mathrm{p}<0.05$. Mean score of depression (4.42) was higher among Physiotherapy students having poor sleep, as compared to those whose sleep was normal, 2.59, $\mathrm{p}<0.05$. Mean score of depression (4.22) was higher among Social work students having poor sleep, as compared to those whose sleep was normal, 2.87, $\mathrm{p}<0.05$ (see Table $3)$.

Table 3. Mean scores and prevalence (percent) of depression and anxiety among the students, according to the study programme

\begin{tabular}{|c|c|c|c|c|c|}
\hline & & Depr & $\overline{A D S}>7)$ & Anxi & $\mathrm{ADS}>7)$ \\
\hline & & $\mathbf{N}(\%)$ & Mean (SD) & $\mathbf{N}(\%)$ & Mean (SD) \\
\hline Oral health & Normal & 1 & 2.55 & 12 & 5.91 \\
\hline$(n=108)$ & $(n=44)$ & $(2.3 \%)$ & $(2.051)$ & $(27.3 \%)$ & $(3.503)$ \\
\hline & Poor sleep & $11 *$ & $4.47 *$ & $36 *$ & $7.98 *$ \\
\hline & $(n=64)$ & $(17.2 \%)$ & $(3.725)$ & $(56.2 \%)$ & $(4.449)$ \\
\hline Beauty Therapy & Normal & 3 & 3.13 & 16 & 7.18 \\
\hline$(n=152)$ & $(n=38)$ & $(7.9 \%)$ & (3.103) & $(42.1 \%)$ & $(3.220)$ \\
\hline & Poor sleep & $26 *$ & $5.31 * *$ & $86 *$ & $10.92 * *$ \\
\hline & $(n=114)$ & $(22.8 \%)$ & (3.190) & $(75.4 \%)$ & (4.439) \\
\hline Nursing & Normal & 3 & 3.26 & 12 & 6.13 \\
\hline$(n=138)$ & $(n=46)$ & $(6.5 \%)$ & $(2.462)$ & $(26.1 \%)$ & $(3.023)$ \\
\hline & Poor sleep & 11 & 4.22 & $61 * *$ & $8.96 * *$ \\
\hline & $(n=92)$ & $(12.0 \%)$ & $(2.828)$ & $(66.3 \%)$ & (3.419) \\
\hline Physiotherapy & Normal & 1 & 2.59 & 8 & 5.96 \\
\hline$(n=110)$ & $(n=27)$ & $(3.7 \%)$ & $(2.080)$ & $(29.6 \%)$ & $(2.875)$ \\
\hline & Poor sleep & 15 & $4.42 *$ & $48 *$ & $8.98 * *$ \\
\hline & $(\mathrm{n}=83)$ & $(18.1 \%)$ & $(2.786)$ & $(57.8 \%)$ & $(3.951)$ \\
\hline Social Work & Normal & $2(6.5 \%)$ & 2.87 & 12 & 6.81 \\
\hline$(n=110)$ & $(n=31)$ & & (3.041) & $(38.7 \%)$ & (3.987) \\
\hline & Poor sleep & 10 & $4.22 *$ & 44 & $8.76 *$ \\
\hline & $(\mathrm{n}=79)$ & $(12.7 \%)$ & (2.827) & $(55.7 \%)$ & $(3.920)$ \\
\hline
\end{tabular}

(italic)

Data is presented as $n(\%)$ or mean $(S D),{ }^{*} p<0.05 .{ }^{*} p<0.001$, as compared to the reference group 
Prevalence of anxiety (56.2\%), as well as mean score of anxiety (7.98) were higher among Oral health students having poor sleep, as compared to those whose sleep was normal, $27.3 \%$ and 5.91, $\mathrm{p}<0.05$. Prevalence of anxiety (75.4\%), as well as mean score of anxiety (10.92) were higher among Beauty Therapy students having poor sleep, as compared to those whose sleep was normal, $42.1 \%$ and 7.18, p<0.05, respectively. Prevalence of anxiety (66.3\%), as well as mean score of anxiety (8.96) were higher among Nursing students having poor sleep, as compared to those whose sleep was normal, $26.1 \%$ and 6.13 , p $<0.001$. Prevalence of anxiety $(57.8 \%)$, as well as mean score of anxiety (8.98) were higher among Physiotherapy students having poor sleep, as compared to those whose sleep was normal, $29.6 \%$ and 5.96, p<0.05, respectively. Mean score of anxiety (8.76) was higher among Social work students having poor sleep, as compared to those whose sleep was normal, 6.81, $\mathrm{p}<0.05$ (see Table 3).

Prevalence of depression (12.2\%) was significantly higher among the first-year students whose sleep was disturbed, as compared to those who had normal sleep (2.9\%), p<0.05 (Table 4). As well as depression mean score was higher (3.93) among those who had disturbed sleep, as compared to normal sleep (2.59), p<0.001. Prevalence of anxiety (56.9\%) was higher among the first-year students who had disturbed sleep, as compared to normal sleep (31.4\%), $\mathrm{p}<0.05$. Anxiety mean score was significantly higher (8.45) among the ones with disturbed sleep, as compared to normal sleep (5.86), $\mathrm{p}<0.001$. Depression was more frequent among the second-year students with sleep disturbances $(18.8 \%)$, as compared to normally sleeping ones $(4.5 \%), \mathrm{p}<0.05$. Depression mean score (4.77) was higher among those having disturbed sleep, as compared to normal sleep (2.87), $\mathrm{p}<0.001$.

Prevalence of anxiety (60.2\%) was greater among the second-year students who had disturbed sleep, as compared to normal sleep (23.9\%), p<0.001. Anxiety mean score was higher (9.11) among the second-year students with disturbed sleep, as compared to normal sleep (6.13), $\mathrm{p}<0.001$.

Depression mean score (5.45) was significantly higher among the third-year students having disturbed sleep, as compared to the students who had normal sleep (3.41), $\mathrm{p}<0.001$. Prevalence of anxiety (79.1\%) was higher among the students with disturbed sleep, as compared to normal sleep (44.9\%), $\mathrm{p}<0.05$. The mean score of anxiety (10.95) was higher among the third-year students whose sleep was poor, as compared to those who had normal sleep (7.47), $\mathrm{p}<0.001$. 


\section{Discussion}

The results of our study revealed higher prevalence of poor sleep (69.9\%) than earlier studies, indicating 16\% prevalence of poor sleep among Malaysian medical students (Zailinawati et al., 2009), 40.6\% in Iran (Ghoreishi \& Aghajani, 2008), 28.2\% in Brazil (Loyaza et al., 2001), 24\% in Mexico (Tafoya et al., 2013), and 40\% in Lithuanian medical students (Preišegolavičiūtè et al., 2010). The exact prevalence of poor sleep in medical students differed between the studies, the difference was influenced by the variety of the measurement tools, significant differences in sociodemographic characteristics of the students and cultural aspects (Azad et al., 2015).

Recent systematic review and meta-analysis (Pacheco et al., 2017) included 59 studies on the prevalence of mental health problems among medical students in Brazil. The prevalence of different mental health problems was assessed, including depression (25 studies, 30.6\%), common mental disorders (13 studies, 31.5\%), poor sleep quality (4 studies, prevalence 51.5\%), excessive daytime sleepiness (4 studies, prevalence $46.1 \%$ ), and anxiety (6 studies, prevalence $32.9 \%$ ). Our study demonstrated different results showing higher prevalence of anxiety (54.2\%) and poor sleep (69.9\%), however, lower prevalence of depression (13.4\%). The differences could be due to small sample and methodological issues.

We aimed to assess sleep quality, anxiety and depression of the students and to compare mean scores according to the year of studying and age. We did not find significant differences in sleep quality according to age and year of studying, however depression and anxiety scores were significantly higher among those studying third year and older students, as compared to first or second year and older students. Actually, there was a study performed among Hong Kong university medical students, which revealed higher year of studying as a factor significantly influencing likelihood of poor sleep (Suen et al., 2008). Other studies aiming to detect factors influencing poor sleep quality underlined other significant factors influencing sleep quality, such as anxiety about study results (Preišegolavičiūtè et al., 2010), irregular work/rest schedules (Feng et al., 2005) and physical problems such as sleep apnea (Pasha \& Khan, 2003).

Earlier scientific research results proved that emotional exhaustion and sleep difficulties negatively influenced physical and psychological well-being of the students in medical school, especially during the first year of studying (Pagnin et al., 2014). This finding can explain the results of our study showing that first year students more often had sleep difficulties, as compared to the second or third year students. Moreover, it was proved (Pagnin et al., 2014) that daytime 
sleepiness, as a consequence of poor sleep, negatively influenced academic efficacy and mood disturbances, just like in our study depression was significantly higher among the students whose sleep was poor. Our study results demonstrating higher depression prevalence among the students having disturbed sleep repeated Sherina (2004) findings showing higher anxiety level among students whose sleep was disturbed, as compared to normal sleep.

Our findings demonstrating associations among students' poor sleep, anxiety and depression supported the results of several other studies, particularly a study in Brazil, which assessed a cumulative risk ratio of 5.47 for minor psychiatric disorders among the medical students who presented with sleepiness, occasional sleep disruption, insomnia or shorter than 7 hours sleep duration (Hidalgo \& Caumo, 2002). Estonian study performed in a group of medical students showed that initial insomnia and daytime sleepiness were associated with depression and anxiety (Eller et al., 2006).

Current study aimed to assess the differences in the prevalence of poor sleep quality, anxiety and depression among study programmes implemented in the Faculty of Health Sciences. We got results indicating that the students of the study programmes Dental Hygiene and Dental Assisting had significantly lower PSQI, anxiety and depression mean scores, as compared to other study programmes, such as Physiotherapy, Nursing, Beauty Therapy and Social work. These results contradicted the results of other surveys, stating that the students of dental schools demonstrate higher levels of depression, obsessive-compulsive disorders, stress-related psychosomatic activity, increased mood disturbances as well as interpersonal sensitivity than age-matched norms (Polychronopoulou \& Divaris, 2005; Rajab, 2001).

There is a study, performed in Poland (Wallace et al., 2013), which supported the results of current study showing that the symptoms of depressive mood and anxiety, as well as poor sleep increased along with studying years. It can be related to transition from basic science training to clinical training difficulties. Final exam stress and future employment (Beiter et al., 2015) could be the reasons for the higher prevalence of depressive symptoms in the final year in all study programmes. Another study performed among nursing students in Saudi Arabia, demonstrated a high prevalence of depressive symptoms (48.2\%), it was either mild (21\%), moderate (17\%), or severe $(11 \%)$. And, differently from our study, the presence and severity of depressive symptoms had a statistically significant association with early academic years $(p<0.000)$ (Al-Faris et al., 2012). 


\section{Conclusions}

Poor sleep and anxiety were more prevalent among the students aged 20 years and older as compared to the students, aged 18 and 19 years. Second and third year students more often had poor sleep or anxiety as compared to the first-year students. Poor sleep and anxiety were more common among Beauty Therapy and Physiotherapy students than among Oral Health Students.

Among the students who slept poorly, symptoms of anxiety and depression were statistically significantly more frequent than those students whose sleep was not disturbed. Depression and anxiety mean scores were statistically significantly higher among the students who had poor sleep, as compared to the ones who had normal sleep, in all age and year of studying groups.

\section{References}

1. Ahrberg, K., Dresler, M., Niedermaier, S., Steiger, A., \& Genzel, L. (2012). The interaction between sleep quality and academic performance. Journal of Psychiatric Research, 46, 1618-1622.

2. Al-Faris, E. A., Irfan. F., Van Der Vleuten, C. P. M., Naeem, N., Alsalem, A., Alamiri, N., Alraiyes, T., Alfowzan, M., Alabdulsalam, A., Ababtain, A., Aljabab, S., Bukhari, M., Alsinaidi, O., \& Alofaisan, Y. (2012). The prevalence and correlates of depressive symptoms from an Arabian setting: A wake up call. Medical Teacher, 34(1), 32-36.

3. Angelone, A. M., Mattei, A., Sbarbati, M., Di Orio, F. (2011). Prevalence and correlates for self-reported sleep problems among nursing students. Journal of Preventive Medicine and Hygiene, 52(4), 201-208.

4. Arora, A., Kannan, S., Gowri, S., Choudhary, S., Sudarasanan, S., \& Khosla, P. P. (2016). Substance abuse amongst the medical graduate students in a developing country. The Indian Journal of Medical Research, 143(1), 101-103.

5. Azad, M. Ch., Fraser, K., Rumana, N., Abdullah, A. F., Shahana, N., Hanly, P. J., \& Turin, T. Ch. (2015). Sleep Disturbances among Medical Students: A Global Perspective. Journal of Clinical Sleep Medicine, 11(1), 69-73.

6. Beiter, R., Nash R, McCrady, M., Rhoades, D., Linscomb, M., Clarahan, M., \& Sammut, S. (2015). The prevalence and correlates of depression, anxiety and stress in a sample of college students. Journal of Affective Disorders, 173, 90-96.

7. Buysse, D. J., Reynolds, C. F., Monk, T. H., Berman, S. R., Kupfer, D. J. (1989). The Pittsburgh Sleep Quality Index (PSQI): A new instrument for psychiatric research and practice. Psychiatry Research, 28(2), 193-213. 
8. Cheung, T., Wong, S. Y., Wong, K. Y., Law, L. Y., Ng., K, Tong, M. T., Wong, K. Y., Ng. M. Y., \& Yip, P. S. (2016). Depression, Anxiety and Symptoms of Stress among Baccalaureate Nursing Students in Hong Kong: A Cross-Sectional Study. International Journal of Environmental Research and Public Health, 13, 779 .

9. Dyrbye, L. N., West C. P, Satele, D., Boone, S., Tan L., Sloan, J., \& Shanafelt T. D. (2014). Burnout among U.S. medical students, residents, and early career physicians' relative to the general U.S. population. Academic Medicine: Journal of the Association of American Medical Colleges, 89(3), 443-451.

10. Elani, H. W., Allison, P. J., Kumar, R. A., Mancini, L., Lambrou, A., \& Bedos, C. (2014). A systematic review of stress in dental students. Journal of Dental Education, 78(2), 226-242.

11. Eller, T., Aluoja, A., Vasar, V., \& Veldi, M. (2006). Symptoms of anxiety and depression in Estonian medical students with sleep problems. Depression and Anxiety, 23, 250-256.

12. Feng, G., Chen, J., \& Yang, X. (2005). Study on the status and quality of sleep-related influencing factors in medical college students. Zhonghua Liu Xing Bing Xue Za Zhi, 26, 328-331.

13. Ghoreishi, A., \& Aghajani, A. H. (2008). Sleep quality in Zanjan university medical students. Tehran University Medical Journal, 66, 61-67.

14. Hidalgo, MP., \& Caumo, W (2002). Sleep disturbances associated with minor psychiatric disorders on medical students. Neurological Science, 23, 35-39.

15. Hope, V., \& Henderson, M. (2014). Medical student depression, anxiety and distress outside North America: a systematic review. Medical Education, 48(10), 963-79.

16. Loyaza, H. M. P., Ponte, T. S., \& Carvalho, C. G. (2001). Association between mental health screening by self-report questionnaire and insomnia in medical students. Arquivos de Neuro-Psiquiatria, 59, 180-185.

17. Mazurek, MB., Melnyk, B., Slevin, C., Militello, L., Hoying, J., Teall, A., \& McGovern, C. (2016). Physical health, lifestyle beliefs and behaviors, and mental health of entering graduate health professional students: Evidence to support screening and early intervention. Journal of the American Association of Nurse Practitioners, 28(4), 204-211.

18. Misra, R., \& McKean, M. (2000). College students' academic stress and its relation to their anxiety, time management, and leisure satisfaction. American Journal of Health Studies, 16, 41-52.

19. Pacheco, J. P., Giacomin, H. T., Tam, W. W., Ribeiro, T. B., Arab, C., \& Italla C. (2017). Mental health problems among medical students in Brazil: a systematic review and meta-analysis. Revista Brasileira de Psiquiatria, 39(4), 369-378.

20. Pagnin, D., De Queiroz, V., Carvalho, Y. T., Dutra, A. S., Amaral, M. B., \& Queiroz, T. T. (2014). The relation between burnout and sleep disorders in medical students. Academic Psychiatry, 38, 438-444.

21. Palatty, P. L., Fernandes, E., Suresh, S., \& Baliga, M. S. (2011). Comparison of sleep pattern between medical and law students. Sleep Hypnptherapy, 13, 1-2. 
10.1515/arhss-2017-0003 Applied Research in Health and Social Sciences: Interface and

Interaction, Vol. 14, No. 1, 2017

22. Pasha, S. N., \& Khan, U. A. (2003). Frequency of snoring and symptoms of sleep apnea among Pakistani medical students. Journal of Ayub Medical College Abbottabad, 15, 23-25.

23. Polychronopoulou , A., \& Divaris K. (2005). Perceived sources of stress among Greek dental students. Journal of Dental Education, 69, 687-692.

24. Preišegolavičiūtè, E., Leskauskas, D., \& Adomaitienė, V. (2010). Associations of quality of sleep with lifestyle factors and profile of studies among Lithuanian students. Medicina, 46(7), 482-489.

25. Rajab, LD. (2001). Perceived sources of stress among dental students at the University of Jordan. Journal of Dental Education, 65(3), 232-241.

26. Sarokhani, D., Delpisheh, A., Veisani, Y., Sarokhani, M. T., Manesh, R. E., \& Sayehmiri, K. (2013). Prevalence of depression among university students: a systematic review and meta-analysis study. Depression Research and Treatment, 37, 38-57.

27. Suen, L. K., Hon, K. L., \& Tam, W. W. (2008). Association between sleep behavior and sleep-related factors among university students in Hong Kong. Chronobiology International, 25, 760-775.

28. Sherina, M. S., Rampal, L., \& Kaneson, N. (2004). Psychological stress among undergraduate medicalstudents. Medical Journal of Malaysia, 59(2), 207-211.

29. Tafoya, S. A., Jurado, M. M., Yepez, N. J., Fouilloux, M., \& Lara, M. C. (2013). Sleep difficulties and psychological symptoms in medicine students in Mexico. Medicina,73, 247-251.

30. Veldi, M., Aluoja, A., \& Vasar, V. (2005). Sleep quality and more common sleep-related problems in medical students. Sleep Medicine, 6(3), 269-275.

31. Wallace, B., Masiak, J., \& Pabis, M. (2013). Depression in medical students: reviewing its prevalence, risk factors, consequences, and management in order to provide student treatment recommendations for the Polish medical education system. Polish Journal of Public Health, 123(3), 259-264.

32. Yusoff, M. S., Abdul, Rahim, A. F., Baba, A. A., Ismail, S. B., Mat, Pa, M. N., \& Esa, A. R. (2013). The impact of medical education on psychological health of students: a cohort study. Psychology, Health \& Medicine, 18(4), 420-430.

33. Zigmond, A. S., \& Snaith, R. P. (1983). The Hospital Anxiety and Depression Scale. Acta Psychiatrica Scandinavica, 67, 361-370.

34. Zailinawati, A. H., Teng, C. L., Chung, Y. C., Teow, T. L., Lee, P. N., \& Jagmonhi, K. S. (2009). Daytime sleepiness and sleep quality among Malaysian medical students. Medical Journal of Malaysia, 64, 108-110. 